\title{
How an obstetric case was instrumental in writing a new chapter in the book of UK medico-legal jurisprudence
}

\author{
Buttigieg GG* \\ Department of Obstetrics and Gynaecology, Faculty of Medicine and Surgery, University of Malta
}

\begin{abstract}
From time to time, there appear jurisprudential enunciations which capture the evolutionary change awaiting the seed of an opportune catalyst. This has been the situation with the legal challenge set up by one woman who had a disastrous outcome to her childbirth. The judgement in Nadine Montgomery v Lanarkshire Health Board, has set in motion jurisprudential implications of as yet, inestimable proportions which are bound to radically affect liability in all spheres of medical liability. It has launched a serious challenge to the Bolam test, even as reined in by the Bolitho principle. Taking the specialty of Obstetrics as basis for case discussion, this article evaluates some shortcomings of the Bolam test which seems out of its depth in the 21 st century. It also views the ruling in Nadine Montgomery as potentially, the beginning of the end of Bolam and the further empowerment of the patient's autonomy.
\end{abstract}

\section{Grandfather bolam}

On reflection, it is a great and wondrous thing that a principle enunciated in 1957 in an English tort case, would hold its own for an odd six decades in such a rapidly evolving discipline as Medicine. Yet it has, in spite of volumes written, expounding the various aspects of its weaknesses. In Bolam v Friern Hospital Management Committee, McNair J ruled that there is no breach of standard of care if a responsible body of similar professionals supports the practice judged even if this did not comply with the established standard of care.

Under this principle, the plaintiff needs to establish that the existence of a duty of care by the defendant to the plaintiff the doctor, through omission or commission, breached that duty of care as defined by a responsible body of similar professionals [1,2]. Criticised for its overreliance on medical testimony and personal judgement of experts, Bolam was subsequently "enriched" in 1997 by the Bolitho Principle.

In Bolitho v. City \& Hackney Health Authority, the plaintiff, a mother of a dead two-year child, claimed that the doctor involved (whose bleep had malfunctioned) would have intubated and saved the child had she been present. The defendant maintained that in this particular case, even if available, she still would not have intubated. The Court applied the Bolam test to the defendant, holding that no breach of duty had been effected. The plaintiff appealed and again the Court upheld the ruling quoting that the opinion tallied with that of similar professionals but further than that with the explanation of the facts as given, the reasoning made sense to the Court. The Court upheld that the doctors' line of action of the defendant was both defensible and logical. The Bolam and Bolitho principles are often employed in tandem, as in fact was done at the very birth of the Bolitho principle.

The Bolam principle did establish a repeatedly acknowledged primacy in English Law- it was applied by the House of Lords in respect of diagnosis in 1985, of treatment 1981, and, with some caveats, the volunteering of information when advising patients on possible treatment in 1992 [2-4]. However, there are situations that taking Bolam and litteram and on its sole premise, the possibility does exist that the courts could potentially not condemn even a foolish practice if this is backed up by a substantial proportion of the members of a particular profession [5]. This is where the Bolitho principle comes into its own. Furthermore, Bolitho rightly made the Court and not the medical fraternity the final arbiter of malpractice or its absence [6].

"Enriched" or "reined in", by the Bolitho test, Bolam has reigned pretty much supremely, since 1957, despite the changing face of medicine through more than half a century of breath-taking scientific progress. Bolam provides the second of the four steps in determining medical negligence:

I. The establishment of a duty of care between the physician and patient.

II. The breaching of this duty of care

III. The causal link between this breach of the duty of care and the harm suffered by the patient

IV. The harm suffered must not be too remote

Numerous obstetric liability cases have had the Bolam test at its pivotal best being applied with regard to the adjudication as to whether duty of care was breached - as judged by peer opinions. In all these cases the Court was dependent on the medical profession to state what the required standard was. One notes here, the uniqueness of this standard setting for cases of a medical nature, which is different to that applied in say cases of liability faced by accountants, architects, mechanical engineers...Furthermore there have been a number of

Correspondence to: Buttigieg GG, Department of Obstetrics and Gynaecology, Faculty of Medicine and Surgery, University of Malta, Malta, Tel: +356 2340 1102; E-mail: george.g.buttigieg@um.edu.mt

Key words: liability, medico-legal, Bolam's test, Bolitho's test, childbirth, carciotocographic monitoring, disclosure, standard of practice

Received: December 06, 2016; Accepted: January 02, 2017; Published: January 07,2017 
cases where the application of the Bolam's test led to a final outcome which some might consider controversial. Among these we find such obstetric liability cases as Hinfey v Salford Health Authority, Gossland v East of England Strategic Health Authority and Smithers v Taunton and Somerset NHS Trust, to mention but a few. Naturally, one must be extremely careful in the analysis of such cases where difficult and complex retrospective obstetric management scrutiny demands great prudence of interpretation and evaluation [7-9].

\section{Challenging bolam in the 21st century}

In Bolam v Friern Hospital Management Committee, the plaintiff claimed liability through medical negligence after suffering serious injuries including acetabular fractures, following flailing about during electro-convulsant therapy at Friern Hospital. He had neither been strapped nor given any muscle relaxant. His basis for negligence was based on the lack of warning about the risks involved and the prevention of damage through strapping and the use of muscle relaxants. Basically, the Court ruled that negligence was not involved because the defendant had performed the procedure along the usage of peer practice. McNair J noted that much, even if not all, expert witnesses favoured neither muscle relaxants nor physical restraint which was actually claimed, could, in fact, actually increase fracture risk. Regarding the disclosure of risks, the Court noted that in common practice, because such risks were uncommon, they were, most often, not discussed beforehand. The Judge reasoned, that, to fall below the appropriate standard, a doctor would have to fail to do what a reasonable peer in the same circumstances would do. Hence the defendant was not liable.

The 1957 judgement has had its fair of criticism, but here, one simply puts it in the arena against one opponent, namely Evidence based medicine (EBM. Making its debut in the 1990's, this landmark concept of practice guidance, became firmly entrenched in 1996 [10]. EBM is defined as the conscientious and judicious use of current best evidence from clinical care research in the management of individual patients. For the last odd twenty years, the concept has gone from strength to strength and is considered, as the only, clinical, way forward. With it, there commenced the erosion of the importance of the concept of peer practice, a concept which seems to have carried more jurisprudential than clinical kudos. And, with the rise of EBM, one may well ask the million-dollar question of what happens when EBM flies in the face of the so-called peer practice [9]?

\section{An obstetric case starts a new jurisprudential chapter}

Nadine Montgomery v Lanarkshire Health Board, concerned the case of a patient suing her obstetrician after a vaginal breech delivery of a baby left disabled with Cerebral Palsy [11]. The patient, a diabetic woman of short stature and carrying a large baby, alleged obstetric negligence in that the doctor did not inform or discuss with her, the risks inherent in a vaginal delivery versus a Caesarean Section. The Court ruled for the plaintiff and rejected the argument of what peer medical practice might have done in similar circumstances. The defendant should have disclosed, before seeking consent for the birth, all the risks and problems of a vaginal birth - risks which in effect came to pass.

However, it would a mistake to limit the implications of the ruling in Nadine Montgomery simply to one of a new jurisprudential principle solely concerning disclosure of information for the purposes of obtaining consent. Especially since, this presents an opportune challenge to a legal principle, long felt by many, to be short, in effecting justice in medical Court cases.

\section{In the words of Badenoch [12]:}

"As for the future of the Bolam test in other fields of clinical practice, I suggest the writing is on the wall. Bolitho rightly marked and reflected modern distaste for the strict application of Bolam, by restoring at least partially the normal judicial function of deciding which of the opposing expert medical opinions is to be preferred and which to be rejected.

Nadine Montgomery was a case instituted by a woman who rightly and justifiably felt that she had been wronged at the sacred moment of childbirth. No amount of awarded money will make her child whole. Yet, her involuntary and unwanted sacrifice has given the medicolegal world a new principle of empowerment to patients, going beyond childbirth liability, beyond informed consent and beyond obstetrics in general. The ensuing principles and their legal implications bear on the crucial issue of who sets medical standards. With Bolam in play, so far, it has been the medical profession itself. The wheel has now turned. Medical standards in the UK will be set by the judges, advised as if and when necessary by experts. It is the judges who, in accordance with established legal principles, will state what, in given circumstances, the right standard of performance should have been.

Nadine Montgomery has in fact brought medical jurisprudence in line with all other professions, trades and crafts. In all such cases, experts enlighten the Court on what is technical, but the Court, thus informed, will rule on what should or should not have been done. This is fair and just. Especially, when medical practice is nowadays, more and more reliant on what is scientifically proven and acceptable.

The law moves slowly, but is right that the final word on medical standard of practice, will lie squarely in the Court's hands. The future of Bolam itself is very much question. No doubt, using Nadine Montgomery as precedent, similar argumentation will be applied to all other aspects of medical liability reaching the Courts. Yesterday it was disclosure of information in Nadyne Montgomery. Tomorrow it will be some aspect of diagnosis or management in the case of John Doe. One woman has been instrumental in setting the ball rolling. Nobody can say when it will stop. Medico-legal history is changing and needed changing. To what extent, only time will tell.

\section{References}

1. Bolam v Friern Hospital Management Committee (1957) 1 WLR 582.

2. Maynard v. West Midlands Regional Health Authority (1985) 1 All E.R. 635.

3. Whitehouse v. Jordan (1981) 1 WLR 246.

4. Sidaway v. Bethlem (1992) BMLR 11.

5. R Jackson (1988) 'Professional Liability'. RSA J 136: 536-546.

6. R Mulheron (2010) 'Trumping "Bolam": A Critical Legal Analysis of Bolitho "Gloss" The Cambridge Law Journal 69: 609-638.

7. Hinfey v Salford Health Authority (1993) 4 Med LR 143.

8. Gossland v East of England Strategic Health Authority (2008) EWHC 2175.

9. Buttigieg GG (2016) Equivocal Court Cardiotocography Weighting in Cerebral Palsy Litigation. J for Med Leg Aff 1: 107.

10. Claridge JA, Fabian TC (2005) History and development of evidence-based medicine. World J Surg 29: 547-553.

11. Montgomery v Lanarkshire Health Board, UK Supreme Court (2015) UK SC 11.

12. Badenoch J (2016) A doctor's duty of disclosure and the decline of 'The Bolam Test': A dramatic change in the law on patient consent. Med Leg J 84: 5-17. [Crossref]

Copyright: (C2017 Buttigieg GG. This is an open-access article distributed under the terms of the Creative Commons Attribution License, which permits unrestricted use, distribution, and reproduction in any medium, provided the original author and source are credited. 